Riqueza e miséria do trabalho no Brasil III. Ricardo Antunes (org.). Coleção Mundo do Trabalho. São Paulo: Boitempo Editorial, 2014, $464 \mathrm{p}$.

\section{Filippina Chinelli}

Fundação Oswaldo Cruz, Escola Politécnica de Saúde Joaquim Venâncio, Laboratório do Trabalho e da Educação Profissional em Saúde, Rio de Janeiro, Brasil <pina.chinelli@gmail.com>

http://dx.doi.org/10.1590/1981-7746-sip00103

Lançado em 2014, em meio à crise socioeconômica, política e moral que o país atravessa, o terceiro volume de Riqueza e Miséria do Trabalho no Brasil, organizado por Ricardo Antunes, demonstra que a dinâmica do capitalismo contemporâneo analisada nos volumes anteriores da obra se aprofundou: o trabalho segue central na produção de valor, ao mesmo tempo em que continua se esfacelando como direito e se acentuam os processos de terceirização, precarização, informalização, ou seja, de vulnerabilização das condições de vida que afetam, em graus variados, os trabalhadores do mundo.

O livro constitui mais uma importante contribuição para a análise do que Antunes denomina de 'laboratório capitalista', realizada através de 25 artigos de autoria de pesquisadores tanto em início de formação quanto de reconhecimento nacional e internacional, combinando, “pesquisas coletivas, reflexões conjuntas, mas preservando o decisivo espaço de autonomia de cada pesquisador" (p. 9).

Tendo como fio condutor a compreensão das "heranças oriundas do padrão tayloriano-fordista de produção" e as "emergências decorrentes dos novos experimentos produtivos que resultam da acumulação flexível e presentes de modo expressivo no universo produtivo brasileiro" (p. 9), os autores se detêm nas transformações do mundo do trabalho e suas repercussões materiais e subjetivas sobre os trabalhadores, com olhos postos no Brasil, mas considerando as configurações que o capitalismo vem assumindo nos países centrais.

Santana assinala na orelha do livro que não se trata mais de analisar essas metamorfoses e transformações no Brasil da última década "como um ente em transição geral de um modo a outro, mas em mudança dentro de um estado já definido que precisa ser conhecido, interpreta- do e transformado". Cabe agora tentar apreender os resultados desse processo, intenção que se revela pela leitura em conjunto dos artigos da coletânea.

Ao contrário das interpretações laudatórias que prometeram um quase paraíso aos trabalhadores do mundo, o que une os textos é uma perspectiva teórica profundamente crítica do mundo do trabalho, assentada no materialismo histórico, conforme delineado logo na primeira parte, cujos artigos apresentam discussões de caráter eminentemente conceitual que articulam, de forma explícita ou não, as interpretações do material empírico no qual se baseiam. Nela, denominada "Sistema global do capital e a corrosão do trabalho", autores como Antunes e Druck, Mézáros, Bihr, Linhart, Alves, entre outros, tratam, de forma rigorosa, de temas como terceirização, trabalho abstrato, precarização, imigração, subjetividade, trabalho imaterial, estranhamento, alienação etc, relacionando-os aos processos que, em escala mundial, produziram o capitalismo flexível, o que vem se dando à custa da segurança material e subjetiva dos trabalhadores e da crescente fragmentação do tecido social, tanto no centro quanto na periferia do sistema, atingindo inclusive aqueles antes protegidos de suas intempéries.

As implicações subjetivas do regime flexível de organização do trabalho são abordadas em vários destes artigos, o que demonstra o interesse crescente da sociologia do trabalho contemporânea pelo tema. É preciso tentar apreender e analisar como o capitalismo flexível se justifica, como também quais são, como funcionam e quais os efeitos sobre os trabalhadores e as sociedades dos insidiosos dispositivos que objetivam o controle e a adesão ativa de todos aos objetivos das empresas.

É disso que se ocupam, por exemplo, Danielle Linhart, Giovanni Alves e Caio Antunes. Na opinião de Linhart, nem mesmo os empregados estáveis das grandes empresas estão a salvo das consequências psicológicas - e também físicas - consequentes aos novos modelos de gestão que produzem o que denomina 'precariedade subjetiva' caracterizada por sentimentos de isolamento, insegurança, angústia experimentados pelos trabalhadores. Em suas palavras, os "assalariados têm medo de não ser capazes, quer ocupem postos altos ou subalternos. Eles sabem que são continuamente avaliados, comparados, 
julgados; sabem que são explicitamente exigidas pela administração moderna a excelência e a capacidade permanente de ir além, de provar que merecem o lugar que têm e se convencerem do próprio merecimento (p. 51)". "Desses dois pontos de vista", acrescenta a autora, "o fracasso torna-se catastrófico, e o medo de enfrentá-lo causa uma angústia real" (p. 51).

Alves, também tendo como preocupação as estratégias gerenciais mobilizadas pela atual organização do trabalho, afirma que o "capitalismo manipulatório", expressão que toma emprestado de Luckács, se esmera na disputa pela captura da subjetividade, processo produzido pela "disseminação de uma pletora de valores-fetiche, expectativas e utopias de mercado que constituem o que denominamos de inovações sociometabólicas, que perpassam não apenas os espaços de produção, mas também o espaço da reprodução social" (p. 55).

Procedendo a uma análise eminentemente teórica com base em Marx e Luckács, Caio Antunes trata da subjetividade em relação ao conceito de alienação. $\mathrm{O}$ autor afirma que a alienação sob o capitalismo repercute em graus diferenciados nos aspectos coletivos e privados, objetivos e subjetivos de todas as esferas da vida contemporânea. Nessa perspectiva e com base em Mészáros, ele ressalta que a alienação, "para além de interpor-se na relação direta que se estabelece entre o homem e a natureza, (...) sobrepõe-se, condiciona, conforma historicamente a categoria trabalho" (p. 127), não permitindo o desenvolvimento pleno da subjetividade humana.

A segunda parte do livro, intitulada "As formas de ser da reestruturação produtiva no Brasil e a nova morfologia do trabalho", traz artigos que se debruçam sobre a configuração atual de diferentes setores produtivos da economia do país. A referência aos textos se limitará aos temas neles analisados, alguns dos quais estreantes quando considerados os volumes anteriores. Abordam-se nesta seção tópicos como construção civil e intelecto coletivo; telemarketing, telecomunicações e a nova divisão internacional do trabalho; prestação de serviços e situação do trabalho no telemarketing e nas telecomunicações brasileiras nos anos 2000; trabalho docente voluntário; trabalho de rua e informalidade; trabalho precarizado de trabalhadores de apoio técnico das artes; divisão sexual e condições de trabalho de vida de mulheres e homens inseri- dos no segmento avícola no contexto de integração de uma grande empresa no setor; trabalho na agricultura canavieira; trabalho das 'caixas' em hipermercados ligados a multinacionais do setor; trabalho degradante dos cortadores de cana.

"Os sindicatos na encruzilhada: ação e resistência dos trabalhadores" é o título da última parte da obra que se ocupa de questões do sindicalismo brasileiro atual. Sória, por exemplo, analisa as relações ambíguas e contraditórias entre a elite do sindicalismo de caráter propositivista e os fundos de pensão, no contexto de refluxo do movimento sindical e dos governos lulistas. Articula as dimensões político-conjuntural e teórico-ideológica para explicar o envolvimento ativo de lideranças sindicais nesse processo sob a justificativa de que, para lutar contra o capitalismo e proteger os interesses dos trabalhadores, era necessário que a gerência dos fundos passasse para as mãos de sindicalistas, o que acabou por promover forte - e, acrescente-se, perigosa - aproximação com o empresariado do país.

Nogueira trata das relações entre trabalhadores, sindicatos e uma empresa multinacional do setor automobilístico paulista, mostrando suas ambiguidades e contradições. Considera que na atualidade elas se caracterizam pelo "paradigma negocial e participativo", mas também conflitivo, "o que indica a formação de um novo corporativismo de tipo societário, legitimado pela própria base operária na fábrica, diferentemente do padrão do sindicalismo corporativista estatal existente no Brasil" (p. 370).

No penúltimo artigo desta parte e também da coletânea, com base em material empírico sobre o trabalho dos teleoperadores paulistanos, Braga analisa as relações que vigem no país entre Estado e sindicatos, com ênfase nos governos lulistas. Em perspectiva semelhante à de Sória, afirma que os sindicatos se tornaram importantes atores no que se refere ao investimento capitalista no país por meio da gestão de fundos salariais e de pensão. O autor ressalta que essa configuração começa a dar sinais de esgotamento, expresso na recente onda de manifestações que se verificou em todo o país. Contudo, embora alguns desses movimentos expressem tendências progressistas, ele reconhece que a "evolução da luta de classe no país é, fundamentalmente, reprodutivista e, em consequência, conservadora" (p. 399). 
Fechando a coletânea, Marcelino se ocupa da atuação sindical de trabalhadores terceirizados de Campinas. Em sua opinião, embora a terceirização resulte em limites às possibilidades de ação dos sindicatos devido à "precariedade das condições de trabalho e da fragmentação das categorias" (p. 401), as dificuldades não são intransponíveis, visto que vários deles conseguem empreender um trabalho combativo e reivindicativo, caso do Sindicato da Construção Civil, diferentemente do Sindicato dos Comerciários, cuja atuação se caracteriza pela conciliação. Sobre as experiências analisadas, Marcelino ressalta que o caráter da ação "não é dada (...) apenas pela composição da base, mas é resultado de uma combinação entre esse elemento e as condições políticas, sociais e econômicas, o peso da estrutura sindical corporativa, o papel desempenhado pelas direções sindicais, o histórico de luta de cada categoria e o desenrolar de enfrentamentos exteriores às empresas e cruciais para a construção de uma atmosfera de embates classistas" (p. 417).

Finalmente cabe ressaltar que Riqueza e miséria do trabalho no Brasil III amplia e enriquece o objetivo da série: dar ao conhecimento dos interessados, sejam alunos e professores da área de humanas, seja o público em geral, as faces atuais do capitalismo brasileiro, constituindo-se em leitura indispensável para todos aqueles que acreditam em sua superação. 